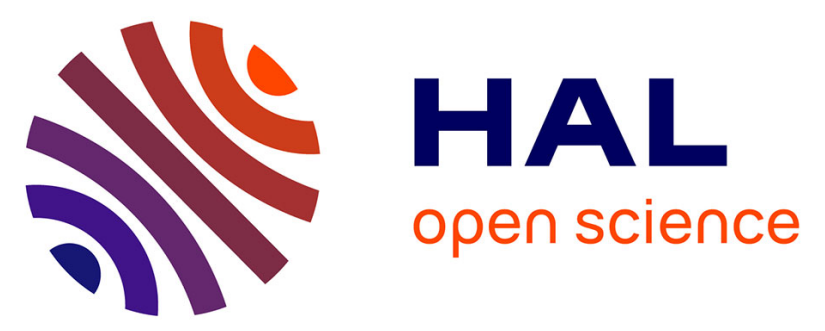

\title{
Validation of a Score for the Detection of Subjects with High Risk for Severe High-Altitude Illness
}

Jean-Paul Richalet, Fabien Pillard, David Le Moa, Daniel Rivière, Philippe

Oriol, Mathias Poussel, Bruno Chenuel, Stephane Doutreleau, Samuel Verges, Sophie Demanez, et al.

\section{To cite this version:}

Jean-Paul Richalet, Fabien Pillard, David Le Moa, Daniel Rivière, Philippe Oriol, et al.. Validation of a Score for the Detection of Subjects with High Risk for Severe High-Altitude Illness. Medicine and Science in Sports and Exercise, 2021, 53 (6), pp.1294-1302. 10.1249/MSS.0000000000002586. hal-03108569

\section{HAL Id: hal-03108569 \\ https://hal.science/hal-03108569}

Submitted on 15 Nov 2021

HAL is a multi-disciplinary open access archive for the deposit and dissemination of scientific research documents, whether they are published or not. The documents may come from teaching and research institutions in France or abroad, or from public or private research centers.
L'archive ouverte pluridisciplinaire HAL, est destinée au dépôt et à la diffusion de documents scientifiques de niveau recherche, publiés ou non, émanant des établissements d'enseignement et de recherche français ou étrangers, des laboratoires publics ou privés.

\section{(c)(1) $\$$}

Distributed under a Creative Commons Attribution - NonCommercial| 4.0 International 


\section{Validation of a Score for the Detection of Subjects with High Risk for Severe High-Altitude Illness}

JEAN-PAUL RICHALET ${ }^{12}$, FABIEN PILLARD ${ }^{3}$, DAVID LE MOAL ${ }^{2}$,DANIELRIVIÈRE ${ }^{3}$, PHILIPPE ORIOL $^{4}$, MATHIAS POUSSEL ${ }^{5}$, BRUNO CHENUEL, STÉPHANE DOUTRELEAU ${ }^{6,7}$, SAMUEL VERGĖ ${ }^{6,7}$, SOPHIE DEMANEZ ${ }^{8}$, MICHEL VERGNION ${ }^{8}$, JEAN-MICHEL BOULET ${ }^{9}$, HERVÉ DOUARD ${ }^{9}$, MARYSE DUPRE ${ }^{10}$, OLIVIER MESLAND ${ }^{10}$, ROMAIN REMETTER ${ }^{11}$, EVELYNE LONSDORFER-WOLF", ALAIN FREY ${ }^{12}$, LOUIS VILCOQ ${ }^{12}$, ANNE NEDELEC JAFFUEL ${ }^{12}$, DAVID DEBEAUMONT ${ }^{13}$, GUY DUPERREX ${ }^{14}$,FRANÇOISLECOQ ${ }^{14}$, CHRISTOPHE HÉDON ${ }^{15}$, MAURICE HAYOT ${ }^{15}$, GUIDO GIARDINI, and FRANÇOIS J. LHUISSIER $^{2,13}$

Institut National du Sport de l'Expertise et de la Performance (INSEP), Pôle médical, Paris, FRANCE; 'Université Sorbonne Paris Nord, UMR INSERM 1272 Hypoxie et poumon, Bobigny, FRANCE; ' Université Paul Sabatier III, Faculté de Médecine Purpan, UMR INSERM U1048 Institut des maladies métaboliques et cardiovasculaires, Hôpital Pierre Paul Riquet, Unité de Médecine du Sport, Toulouse, FRANCE; Institut Régional de Médecine et d'Ingénierie de Sport, Médecine du sport et Myologie, CHU Saint-Etienne, Saint-Etienne, FRANCE; 'Centre Hospitalier Régional Universitaire de Nancy, Centre Universitaire de Médecine du Sport et Activité Physique Adaptée, Service des Explorations de la Fonction Respiratoire, Université de Lorraine, EA 3450 Développement, Adaptation et Handicap, Nancy, FRANCE; 'Université Grenoble Alpes, INSERM U1042 Hypoxie-Physiopathologies cardiovasculaires et respiratoires (HP2), Grenoble, FRANCE; 'CHU Grenoble Alpes, UM Sport et Pathologies, hôpital Sud, Echirolles, FRANCE; 'Centre de physiologie de l'effort—CB Move Herve-Julémont, BELGIUM; 'Hôpital cardiologique, Service maladies coronaires, tests d'effort et readaptation, Pessac, FRANCE; ${ }^{10}$ Institut Régional de Médecine du Sport, CHU Nantes, PHU 10, Hôpital Saint Jacques, Nantes, FRANCE; "Centre Hospitalier Universitaire de Strasbourg, Service de Physiologie et EFR, Nouvel Hôpital Civil, Strasbourg, FRANCE; Centre Hospitalier Intercommunal Poissy/Saint-Germain, Service Médecine du Sport, Site Saint Germain, Saint-Germain en Laye, FRANCE; ${ }^{13}$ Centre Hospitalo-Universitaire de Rouen, Hôpital Charles Nicolle, CIC-CRB 1404, Unité de physiologie respiratoire et de l'exercice, Rouen, FRANCE; 'Hôpitaux du Pays du Mont Blanc, Consultation de Médecine et Traumatologie du Sport, Montagne, Sallanches, FRANCE; ${ }^{15}$ UMR INSERM U1046-CNRS 9214-PhyMedExp, Université de Montpellier, CHU Arnaud de Villeneuve, Montpellier, FRANCE; ${ }^{16}$ Ospedale U. Parini-Azienda USL della Valle d'Aosta, Centro di Medicina e Neurologia di Montagna, Aosta, ITALY; and ${ }^{17}$ Assistance Publique-Hôpitaux de Paris, Hôpital Jean Verdier, Médecine de l'exercice et du sport, Bondy, FRANCE

\section{ABSTRACT}

RICHALET, J.-P., F. PILlARD, D. LE MOAL, D. RIVIÈRE, P. ORIOL,M. POUSSEL, B. CHENUEL, S. DOUTRELEAU, S. VERGÈS, S. DEMANEZ, M. VERGNION, J.-M. BOULET, H. DOUARD, M. DUPRÉ, O. MESLAND, R. REMETTER, E. LONSDORFER-WOLF, A. FREY, L. VILCOQ, A. NEDELEC JAFFUEL, D. DEBEAUMONT, G. DUPERREX, F. LECOQ, C. HÉDON, M. HAYOT, G. GIARDINI, and F. J. LHUISSIER. Validation of a Score for the Detection of Subjects with High Risk for Severe High-Altitude Illness. Med. Sci. Sports Exerc., Vol.53, No.6, pp. 00-00, 2021. Purpose: A decision tree based on a clinicophysiological score (severe high-altitude illness (SHAI) score) has been developed to detect subjects susceptible to SHAI. We aimed to validate this decision tree, to rationalize the prescription of acetazolamide (ACZ), and to specify the rule for a progressive acclimatization. Methods: Data were obtained from 641 subjects in 15 European medical centers before and during a sojourn at high altitude. Depending on the value of the SHAI score, advice was given and ACZ was eventually prescribed. The outcome was the occurrence of SHAI at high altitude as a function of the SHAI score, ACZ prescription, and use and fulfillment of the acclimatization rule. Results: The occurrence of SHAI was $22.6 \%$, similar to what was observed $18 \mathrm{yr}$ before (23.7\%), whereas life-threatening forms of SHAI (high-altitude pulmonary and cerebral edema) were less frequent $(2.6 \%-0.8 \%, \mathrm{P}=0.007)$. The negative predictive value of the decision tree based was $81 \%$, suggesting that the procedure is efficient to detect subjects who will not suffer from SHAI, 


\section{A}

$n$ increasing number of sea-level residents visit areas above $4000 \mathrm{~m}$ of altitude for leisure, sport-base tourism, or work. They may suffer from severe acute mountain sickness (AMS), high-altitude pulmonary (HAPE) or cerebral (HACE) edema (1). The aforementioned clinical outcomes have been aggregated in a clinical entity called severe high-altitude illness (SHAI), characterized by a serious negative effect on physical activity. A number of studies have proposed various markers of susceptibility to AMS but failed to demonstrate any predictability of these markers, mainly because they were obtained from a limited number of subjects.

From a cohort of 1017 sea-level natives, we developed a risk prediction score of SHAI (SHAI score) combining clinical and physiological factors obtained from a hypoxia submaximal exercise test before their stay at high altitude (HA; Table 1) $(2,5)$. This score was the first to predict the risk of SHAI in a large cohort of sea-level residents visiting HA regions $(3,5)$ and was then used in subsequent studies (6-8). A decision tree was designed to standardize the use of the SHAI score 1) to detect high-risk subjects for SHAI and 2) to prescribe advice for acclimatization and eventually acetazolamide (ACZ) for the prevention of SHAI (Fig. 1) (4). ACZ is the most efficient drug commonly given for the prevention of SHAI but may have some side effects and contraindications (9-11).

Therefore, the main goal of this decision tree was to minimize the risk of SHAI while also minimizing the use of ACZ. A commonly given recommendation is to climb gradually, but the threshold given for the daily altitude gain in the literature varies from 300 to $600 \mathrm{~m}$ $(1,12)$. When an advice is given with a lower and an upper range, people have a clear tendency to conform to the upper range, putting them at a higher risk. Moreover, the determination of this daily altitude gain is not clear in the literature.

The objective of the present study was to validate the decision tree in a large population of subjects explored in a multicenter network (multiSHAI) gathering 15 centers in France, Belgium, and Italy. Our goal was to standardize the use of SHAI score and the advice given to the subjects before their stay at HA. Specific objectives were to propose 1) a validated rule for an optimized prescription of ACZ and 2) a validated rule for the daily altitude gain.

\section{METHODS}

The protocol was approved for all centers involved in the study by the "Comité de Protection des Personnes du Sud-Ouest et Outre-Mer IV" Ethics Committee. All participants provided written informed consent before participation.

\section{Subjects}

A total of 1216 subjects were recruited during a routine mountain medicine consultation performed before their sojourn at HA (for tourism, trekking, expedition, or work) in 15 medical centers in France, Belgium, and Italy from August 2017 to December 2019. All subjects coming to the routine mountain medicine consultation were invited to participate in the study, as far as their maximal altitude objective was above $4000 \mathrm{~m}$ and their minimum duration of stay above $3500 \mathrm{~m}$ was $2 \mathrm{~d}$.

\section{Study Protocol}

Each subject went through a standard medical consultation and performed a hypoxia exercise test, as previously described $(2,6)$. They were given a field questionnaire to fill out on a daily basis during their stay at HA. Among them, $655(54 \%)$ sent back their questionnaire after their sojourn at HA.

\section{Data Collection}

Computation of the SHAI score. The SHAI score was calculated as previously described (3). Items entering the score are shown in Table 1. The value of the score and the threshold to define high-susceptible and low-susceptible subjects were shown to depend on two specific conditions: -subjects with previous experience at HA (daytime maxi $\urcorner$ mal altitude reached $\geq 4000 \mathrm{~m}$, nighttime (sleep) maximal altitude reached $\geq 3500 \mathrm{~m}$ ) on two occasions -subjects without such experience 


\begin{tabular}{|c|c|c|}
\hline Item & $\begin{array}{l}\text { Subjects with } \\
\text { Previous } \\
\text { Experience } \\
\text { at High Altitude }\end{array}$ & $\begin{array}{l}\text { Subjects without } \\
\text { Previous } \\
\text { Experience } \\
\text { at High Altitude }\end{array}$ \\
\hline History of SHAI & 2.5 & \\
\hline Plamed daily altitude gain (>400 m per night) & 2 & 2 \\
\hline History of migraine & 1.5 & 0 \\
\hline $\begin{array}{l}\text { Geographical location (Aconcagua, } \\
\text { Ladakh-Zanskar, Mont-Blanc) }\end{array}$ & 1 & 0.5 \\
\hline Age $<46$ yr & 0.5 & 0 \\
\hline Female sex & 0 & 0.5 \\
\hline Regular endurance physical activity ${ }^{a}$ & 0.5 & 1 \\
\hline HVRe $\left(L \cdot \mathrm{min}^{-1} \cdot \mathrm{kg}^{-1}\right)<0.68$ & 3 & 3 \\
\hline HVRe $\left(L \cdot \mathrm{min}^{-1} \cdot \mathrm{kg}^{-1}\right) \geq 0.68$ and $<0.94$ & 1 & 1 \\
\hline HCRe (bpm. $\%^{-1}$ ) $<0.72$ & 1 & 1 \\
\hline HCRe $\left(\mathrm{bpm} \cdot \%^{-1}\right) \geq 0.72$ and $<0.95$ & 0 & 1 \\
\hline$\Delta \mathrm{SaO}_{2}$ Exercise $(\%) \geq 24$ & 0 & 2 \\
\hline$\Delta \mathrm{SaO}_{2}$ Exercise $(\%) \geq 19$ and $<24$ & 0 & 1 \\
\hline Threshold to define high susceptibility & $>5$ & $>5.5$ \\
\hline
\end{tabular}

Numerical values of thresholds for $\mathrm{HVRe}, \mathrm{HCRe}$, and $\Delta \mathrm{SaO}_{2}$ Exercise were determined in previous publications (2-4).

$\triangle \mathrm{SaO}_{2}$ Exercise, decrease in arterial $\mathrm{O}_{2}$ saturation in hypoxia at exercise; $\mathrm{HCRe}$, cardiac response to hypoxia at exercise; HVRe, ventilatory response to hypoxia at exercise.

${ }^{a}$ At least 40 min of intense aerobic exercise three times a week

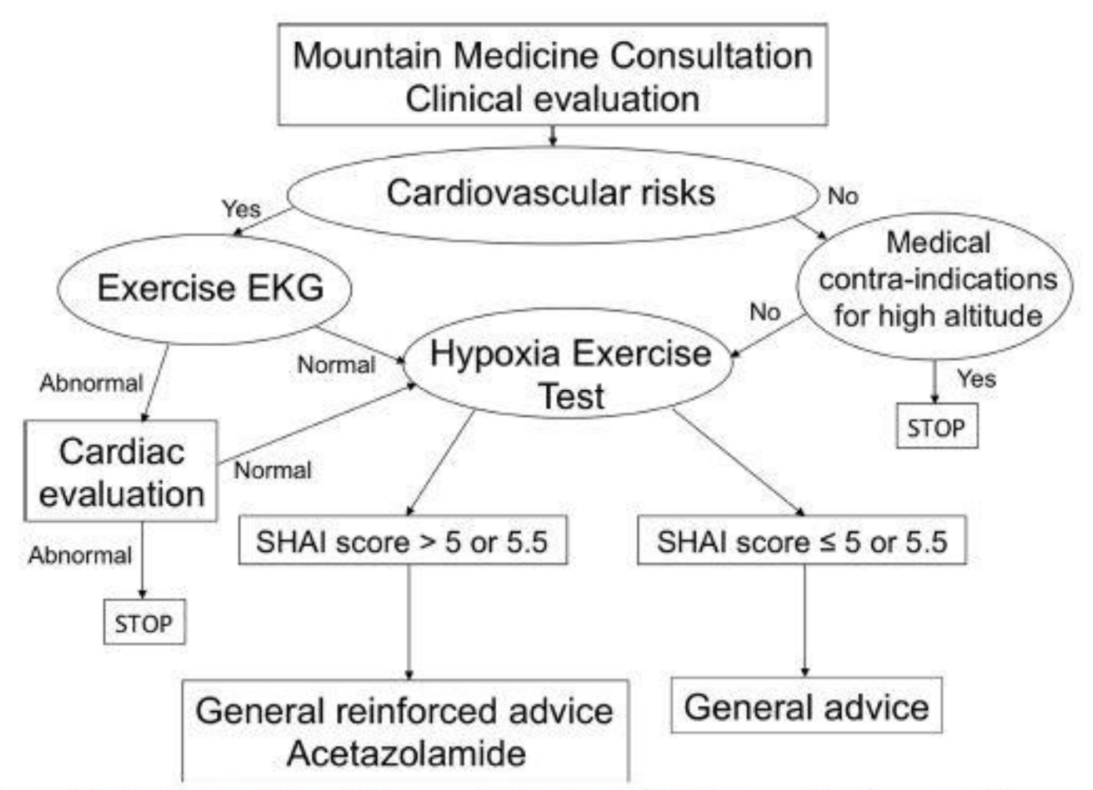

FIGURE 1-Decisional tree used during the mountain medicine consultation. In case of the absence of cardiovascular disease or any other medical contraindication for HA, the hypoxia exercise test is performed and the SHAI score calculated (see text for details). When the score is below the threshold ( 5 for subjects who have a previous experience at high altitude, 5.5 for those who do not), general advice for prevention of acute altitude illness is given: limit intense exercise, good hydration, respect the $400-\mathrm{m}$ rule of acclimatization, avoid hypnotics, and so on. When the score is above the threshold, 1 ) advice are reinforced, insisting on the potential risk of severe manifestations if these advices are not followed, and 2) ACZ is given for a preventive use: 125 mg B.I.D. (morning and midday), starting the day before reaching $3000 \mathrm{~m}$ and continuing until the day when the maximal altitude is reached, but not longer than $7 \mathrm{~d}$. 
medical consultation. From the analysis of the questionnaire, the following information was derived: -highest altitude reached

-highest daily altitude gain in the first 2 wk of the stay over $3000 \mathrm{~m}$ (after $2 \mathrm{wk}$, the acclimatization process is sup-posed to be completed). It was calculated as the maximal difference of sleeping altitudes between two consecutive nights, considering the mean of two successive daily intervals. For example, the following calculation was done for two given profiles of ascent:

Night 1: 3000 m - Night 2: 3800 m - Night 3: 3900 m. Calculated gain: 450 m/night Night 1: 3000 m Night 2: $3800 \mathrm{~m}$ - Night 3: $3400 \mathrm{~m}$. Calculated gain: $200 \mathrm{~m} / \mathrm{night}$

If the night before the first night above $3000 \mathrm{~m}$ (i.e., $3800 \mathrm{~m}$ ) is lower than $3000 \mathrm{~m}$ (i.e., $2500 \mathrm{~m}$ ), the value for this night is taken as $3000 \mathrm{~m}$, assuming that up to $3000 \mathrm{~m}$, the climb does not need a progressive acclimatization. The $400-\mathrm{m}$ rule is considered fulfilled if the daily altitude gain is equal or lower than $400 \mathrm{~m}$.

-The Lake Louise score (LLS) to define AMS (13). LLS was calculated from five items (headache, digestive symptoms, fatigue, dizziness, sleep disturbances) quoted from 0 to 3 . The total score is the sum of the five items and allows to define three levels of outcome: 0-2, no or mild AMS; 3-5, moderate AMS; and 6 and above, severe AMS. The functional item (0-3) is used to evaluate the impact of the symptoms on the activity of the subject.

-HAPE was defined by the presence of clinical signs of respiratory distress (dyspnea, cyanosis, rales), confirmed by a thorax x-ray upon descent to low altitude. HACE was defined by clinical signs of neurological deficit (ataxia, mental confusion). The diagnosis of HAPE or HACE was always confirmed by an expert, either on the spot where the disorder occurred or later on when hospitalized.

-The presence of localized peripheral edema -The preventive use of ACZ during the stay -The personal feeling of the subject if he or she significantly suffered from intolerance to HA and if his/her symptoms led him/her to seek medical advice

SHAI outcome was defined if the subject had a maximal LLS of 6 and above or HAPE or HACE.

\section{Quality Control}

Independently, the clinical and physiological database as well as the field questionnaires was analyzed for quality control, identifying missing or uninterpretable data and incorrect values for physiological variables. Data from 14 subjects were rejected, and therefore, 641 subjects were included in the analysis.

\section{Decision Tree}

From our 20-yr experience of mountain medicine consultation and hypoxia exercise test, we designed a decision tree adapted for people aiming to visit HA regions (4). This algorithm is presented in Figure 1. The first part of the tree is the standard medical consultation aiming at identifying cardiovascular risk factors and for medical contraindications for $\mathrm{HA}$, as proposed by various authors $(14,15)$. Then, the hypoxia exercise test is performed and the SHAI score is calculated for each individual, integrating the estimated possibility to respect the 400-m rule for daily altitude gain. If the SHAI score is higher than the susceptibility threshold, ACZ is prescribed (twice $125 \mathrm{mg} \cdot \mathrm{d}-1$-morning and midday-starting the day before reaching $3000 \mathrm{~m}$ and continuing until the day when the highest altitude is reached but not longer than $7 \mathrm{~d}$ ). The threshold has been previously defined as 5.5 for subjects without previous experience of stay at HA (day altitude $\geq 4000 \mathrm{~m}$, night altitude $\geq 3500 \mathrm{~m}$, on two occasions) and 5 for subjects who have such experience (6). Whatever the score, standard recommendations are given to all subjects: respect of the 400-m rule, reducing physical activity at the beginning of the stay over $3000 \mathrm{~m}$, good hydration, and avoid hypnotics. Patients with a history of allergy for ACZ or any sulfonamide are not given ACZ. Caution is taken with pregnant women, patients on diuretics, patients with recurrent kidney stones, and those at risk for retinal detachment. Altogether, when both the decision tree (ACZ use if high susceptible) and the $400-\mathrm{m}$ rule were respected, only $12 \%$ of the subjects suffered from SHAI as compared with $27 \%$ if the recommendations were not respected $(P<0.001$; Fig. 3$)$.

As expected, subjective appreciation of tolerance to HA was associated with the occurrence of SHAI: difficulties for acclimatization were reported in $55 \%$ of subjects who suffered from SHAl compared with only $14 \%$ in subjects without SHAI (Table 3 ). Among subjects with SHAI, $13 \%$ had a field medical consultation, whereas only $2 \%$ of SHAl-free subjects did (Table 3 ).

Justification of the threshold for the daily altitude gain rule. The highest daily altitude gain in the first $2 \mathrm{wk}$ at HA was recorded for each subject, and the relative frequency is reported in Figure 4A for subjects who suffered (SHAl+) or not (SHAI-) from SHAI. The number of SHAl+ subjects exceeds the number of 
SHAl- subjects above $400 \mathrm{~m}$ (Fig. 4A). This threshold was confirmed by the calculation of the cutoff value of the daily altitude gain by maximizing the Youden index (Fig. 4B). A clear cutoff for daily altitude gain is therefore $400 \mathrm{~m}$.

Compliance markers. Compliance of the physician with the SHAl score to prescribe ACZ was $75 \%$. Compliance of the subject with the prescription of ACZ by the physician was $73 \%$. Among subjects who were prescribed $A C Z, 17 \%$ did not use it, whereas $9 \%$ of subjects who were not prescribed $A C Z$ ef $f$ fectively took it $(P<0.001)$. Altogether, the use of $A C Z$ was in accordance with the SHAl score for $70 \%$ of all subjects. Complinances to SHAl score and to prescription were not influenced by the occurrence of SHAI. Compliance of the physician to SHAI score was higher when subjects took ACZ $(\mathrm{P}=$ $0.013)$, whereas compliance of the subject to the prescription was higher when $A C Z$ was used $(P=$ 0.009). Among high-susceptible subjects

TABLE 2. General characteristics of the population.

\begin{tabular}{lccc}
\hline & Female & Male & $\boldsymbol{P}$ \\
\hline No. subjects & 292 & 349 & \\
Age, yr & $48.8 \pm 14.6$ & $51.8 \pm 13.9$ & 0.008 \\
Body mass index, kg-m ${ }^{-2}$ & $22.2 \pm 3.0$ & $24.4 \pm 2.9$ & $<0.001$ \\
Coronary diseases & 1 & 6 & 0.13 \\
Systemic hypertension & $15(5.1)$ & $42(12.0)$ & 0.002 \\
Raynaud syndrome & $28(9.6)$ & $3(0.9)$ & $<0.001$ \\
Hypercholesterolemia & $16(5.5)$ & $41(11.7)$ & 0.005 \\
Asthma & $14(4.8)$ & $20(5.7)$ & 0.59 \\
Bronchopulmonary diseases & $7(2.4)$ & $6(1.7)$ & 0.54 \\
Allergy & $90(30.9)$ & $93(26.6)$ & 0.23 \\
Perinatal events & $2(0.8)$ & $8(2.6)$ & 0.11 \\
Migraine & $35(12.0)$ & $25(7.2)$ & 0.037 \\
Menopause & $148(53.4)$ & & \\
Smoking & $28(9.6)$ & $29(8.3)$ & 0.57 \\
Sleep apneas syndrome & $6(2.1)$ & $14(4.0)$ & 0.16 \\
Snoring & $40(13.7)$ & $106(30.4)$ & $<0.001$ \\
Regular endurance training & $94(32.2)$ & $154(44.1)$ & 0.002 \\
Previous stay at HA & $106(36)$ & $157(45)$ & 0.026 \\
Previous SHAI if previous stay & $21(20)$ & $24(15)$ & 0.34 \\
Planned altitude, m & $5250 \pm 753$ & $5366 \pm 777$ & 0.06 \\
SHAl score & $5.1 \pm 2.3$ & $4.7 \pm 2.0$ & 0.03 \\
LLS & $4.0 \pm 2.5$ & $3.8 \pm 2.6$ & 0.42 \\
Presence of SHAl & $64(22.0)$ & $81(23.0)$ & 0.70 \\
Peripheral edema & $59(20.2)$ & $34(9.7)$ & $<0.001$ \\
Subjective feeling of intolerance & $71(24.3)$ & $80(22.9)$ & 0.68 \\
Medical consultation & $9(3.1)$ & $20(5.7)$ & 0.11 \\
Highest altitude reached & $5178 \pm 738$ & $5223 \pm 744$ & 0.46 \\
Highest daily altitude gain & $420 \pm 163$ & $418 \pm 182$ & 0.88 \\
Preventive use of ACZ & $141(48)$ & $138(40)$ & 0.026 \\
Compliance to prescription & $217(74)$ & $253(73)$ & 0.60 \\
\hline
\end{tabular}

Values presented are mean $\pm S D$ or number (percentage). $P$ value is calculated via unpaired Student's $t$-test for continuous variables and via $x^{2}$ or Fisher's exact test for categorical variable. 
TABLE 3. Outcomes in the four groups of subjects according to ACZ use and occurrence of SHAI.

\begin{tabular}{|c|c|c|c|c|c|c|}
\hline & \multicolumn{2}{|c|}{ No Preventive Use of ACZ } & \multicolumn{2}{|c|}{ Preventive Use of ACZ } & \multirow{2}{*}{$\frac{P}{\text { ACZ Effect }}$} & \multirow{2}{*}{$\frac{P}{\text { SHAI Eflect }}$} \\
\hline & No SHAI & Presence of SHAI & No SHAI & Presence of SHAI & & \\
\hline No. subjects & 282 & 80 & 214 & 65 & & \\
\hline SHAl score & $3.84 \pm 1.92$ & $4.64 \pm 2.18$ & $5.83 \pm 1.90$ & $6.36 \pm 1.67^{\star \star \star}$ & $<0.001$ & $<0.001$ \\
\hline LLS & $2.92 \pm 1.58$ & $7.69 \pm 1.54$ & $2.70 \pm 1.52$ & $7.40 \pm 1.93^{\star \star \star}$ & 0.075 & $<0.001$ \\
\hline Functional item & $0.37 \pm 0.65$ & $1.43 \pm 1.00$ & $0.52 \pm 0.77$ & $1.80 \pm 1.06^{\star \star \star}$ & 0.001 & $<0.001$ \\
\hline No or mild AMS & $107(38)$ & $0(0)$ & $103(48)$ & $0(0)$ & & \\
\hline Moderate AMS & $175(62)$ & $0(0)$ & $111(52)$ & $0(0)$ & & \\
\hline Severe AMS & 0 & 80 & 0 & 65 & & \\
\hline HAPE & $0(0)$ & $2(2.4)$ & $0(0)$ & $3(4.7)$ & & \\
\hline HACE & $0(0)$ & $0(0)$ & $0(0)$ & $0(0)$ & & \\
\hline Peripheral edema & $32(11)$ & $19(24)$ & $25(12)$ & $17(26)^{\star \star}$ & 0.73 & $<0.001$ \\
\hline Subjective feeling of severe AMS & $39(14)$ & $45(56)$ & $32(15)$ & $35(54)^{\star \star \star}$ & 0.81 & $<0.001$ \\
\hline Medical consultation & $6(2)$ & $8(10)$ & $5(2)$ & $10(15)^{\star \star \star}$ & 0.36 & $<0.001$ \\
\hline Maximal altitude reached, m & $5097 \pm 747$ & $5424 \pm 678$ & $5212 \pm 749$ & $5352 \pm 688^{\star \star}$ & 0.21 & 0.001 \\
\hline Maximal daily altitude gain, m & $388 \pm 184$ & $493 \pm 170$ & $413 \pm 152$ & $478 \pm 160^{\star \star \star}$ & 0.26 & $<0.001$ \\
\hline Compliance to SHAI score & $217(77)$ & $67(84)$ & $146(68)$ & $49(75)$ & 0.013 & 0.10 \\
\hline Compliance to prescription & $197(70)$ & $54(68)$ & $171(80)$ & $48(74)$ & 0.009 & 0.36 \\
\hline
\end{tabular}

Values presented are mean \pm SD or number (percentage). $P$ value is calculated as indicated in the Statistical Analysis section (ANOVA or $x^{2}$ test when appropriate).

${ }^{*} P<0.01$, SHAl with ACZ vs no SHAl without ACZ

$\star \star \star P<0.001$, SHAl with ACZ vs no SHAl without ACZ.

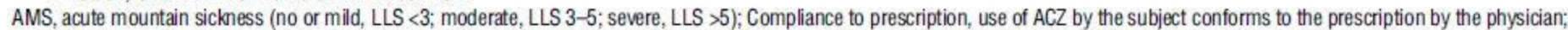

Compliance to SHAl score, prescription of ACZ by the physician conforms to SHAI score vs threshold; Functional item, functional item (0-3) of the LLS; NA, not applicable.

(SHAl score > threshold), $16 \%$ did not have a prescription of ACZ, and finally $33 \%$ did not take ACZ. Among low-susceptible subjects (SHAl score $\leq$ threshold), $31 \%$ had a prescription ACZ, of whereas $29 \%$ effectively took $A C Z$

\section{DISCUSSION}

This study is the first multicenter attempt to validate the subjects preventive measures for high-altitude illness in a large cohort $A C Z, .(N=641)$ of persons planning to visit $H A(>4000 \mathrm{~m})$ regions.

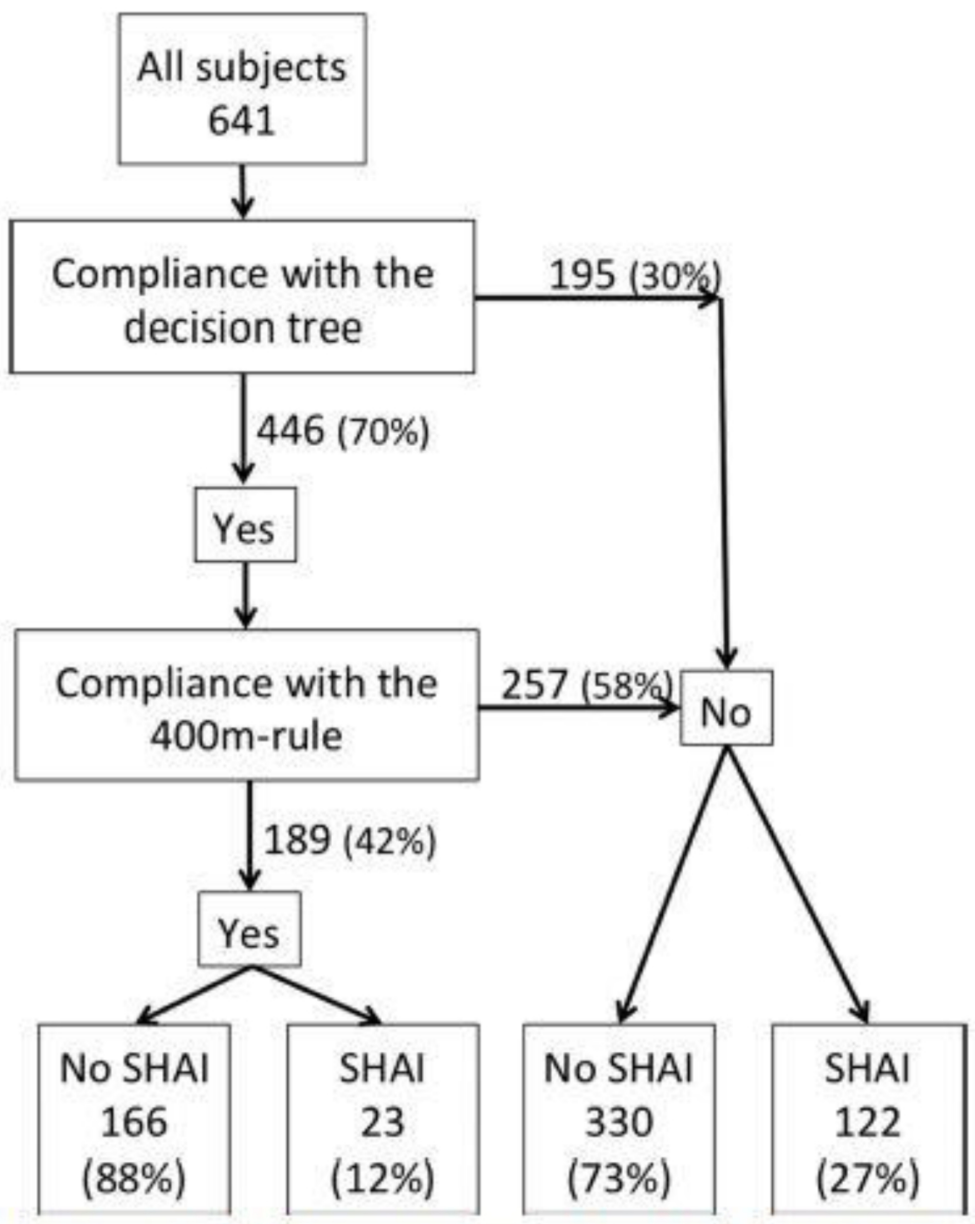

FIGURE 3 - Classification of subjects folkw ing the compliance with the decision tree and the 400-m ruk. In each block is the number of subjects (percentage of above population size).

General characteristics of the population studied did not evidence obvious differences when compared 
with a general population. We compared the main characteristics of our population who returned their questionnaire $(n=641)$ with the overall population initially included in the study $(n=1216)$. There was no difference in age (50 \pm 14 vs $46 \pm 15 \mathrm{yr}$ ), in sex ratio (male/female) (1.2 vs 1.3), in the proportion of subjects with previous SHAI (7\% vs $8 \%)$, or in the proportion of high-susceptible subjects (39\% vs $36 \%)$. Therefore, there was apriorino bias in the analysis of the subgroup that returned the questionnaire. No significant sex effect was found for the occurrence of severe AMS, as found in some studies $(3,17)$ but not in others $(2,18,19)$. All five subjects who presented HAPE were men; however, this limited number did not allow us to draw any conclusion. Peripheral edema was approximately two times more frequent in women than in men, as previously demonstrated (8). When comparing the occurrence of high-altitude illness in the present study with data previously obtained with the same methodology between 1992 and 2008 (2), the occurrence of SHAI was insignificantly reduced (23.7\%-22.6\%), whereas the occurrence of HAPE (1.7\%-0.8\%) and HACE (1\%-0\%) was drastically reduced. The overall decrease in life-threatening forms of altitude sickness in these two large cohorts $(2.7 \%-0.8 \%, P=0.007)$ is encouraging, although the small number of affected subjects makes it difficult to attribute to the mountain medicine consultation (i.e., better information about susceptibility given during this medical visit).

The decision tree and the prescription of ACZ. We propose a decision tree based on the individual SHAl score, which had already been proven to detect persons susceptible to severe high-altitude illness (3). The efficiency of the decision tree cannot be evaluated by standard indices used in binary classification tests because it includes a main intervention (prescription of ACZ depending on the SHAI score) aiming at decreasing the occurrence of the outcome (SHAl at HA). As it was not ethical to compare a treated group (recommendations including ACZ) with an untreated group (no recommendation), the effectiveness of the decision tree was evaluated by studying the occurrence of SHAI in subjects who complied with the protocol. Our main result is that the SHAl score obtained during the presojourn visit is in good agreement with the occurrence of SHAl during the sojourn at HA. Participants who suffered from SHAI in spite of preventive use of ACZ showed a much higher SHAI score (6.36) than those who did not suffer from SHAl without taking ACZ (3.84). The low positive predictive value $(29 \%)$ is expected because subjects detected as high susceptible will be given particular advice to limit their risk of SHAl during their stay at HA. Furthermore, these subjects who have identified themselves as being at high risk will probably be more cautious. The high negative predictive value (81\%) confirms that low-risk subjects have a low probability to develop SHAI and that the procedure is efficient to detect subjects who will not suffer from SHAI, therefore limiting the use of ACZ.

Precise value of maximal daily altitude gain. The daily altitude gain is a well-established determinant factor for the occurrence of SHAI (20-22), although the precise rule to be respected has not been well defined (23). The gap between 300 and $600 \mathrm{~m}$ given in the literature seems much too large if we consider that the great majority of observed altitude gains lie between these values. As shown in Figure 4A, the relative frequency of SHAl is reduced only in the strict range 0 to $400 \mathrm{~m}$, confirming that the threshold for the golden rule "Do not go too high too fast" should be $400 \mathrm{~m}$. This was confirmed by the Youden index (Fig. 4B). In fact, from our first study about risk factors for high-altitude sickness in 1988 and in the following studies, we used a strict threshold of $400 \mathrm{~m}(2-4,8,24)$. Thus, we propose the following rule: "Daily altitude gain should not be higher than $400 \mathrm{~m}$ above $3000 \mathrm{~m}$, at the beginning of the stay at HA. This daily altitude gain is computed as the mean between two consecutive day-intervals. In other words, the two-day (three-night) altitude gain should not exceed $800 \mathrm{~m}$." The limited effect observed in high-susceptible subjects respecting the 400-m rule suggests that in this high-risk category, respecting the 400-m rule cannot fully counterbalance individual susceptibility. 


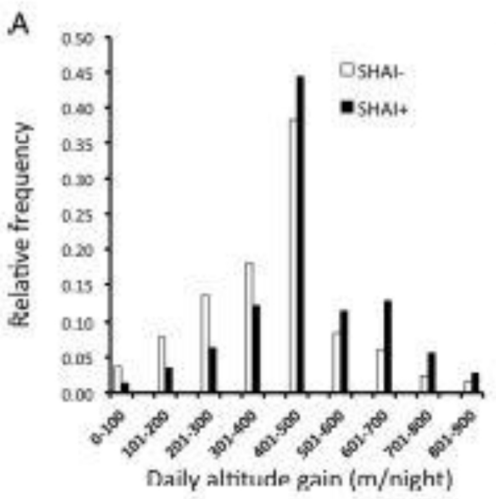

B

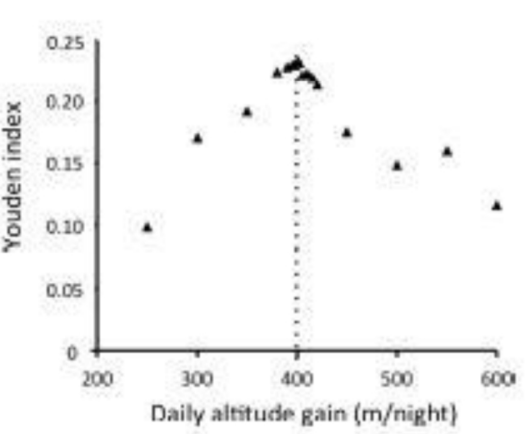

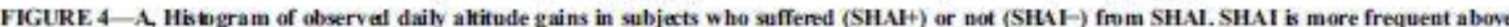
$400 \mathrm{~m}$ of daily altitude gain. See text for the exact cakculation of daily altitude gain. B, Computation of the Yourlen index $(-$ Sensitivity + Specificity -1$)$ as a function of the threshokl for daily altitude gain. The maximal value of the index is observed for a 490 - $m$ threshok.

Compliance with decision tree and with prescription. The compliance of the physicians with the decision tree was not perfect because $25 \%$ of ACZ prescription was not in accordance with the SHAI score. Some physicians had a clear tendency to prescribe $A C Z$, whereas the score did not warrant prescription. Similarly, $27 \%$ of the subjects did not follow the physician's prescription. Altogether, the use of ACZ did not conform to the value of the SHAl score in $30 \%$ of all subjects. Physicians seem to overprescribe $A C Z$, probably because they think it will reduce the risk even in low-risk subjects. Subjects seem to underuse ACZ when prescribed, either for ethical reasons or because they fear side effects.

Limitations. The outcome in field conditions is evaluated through the LLS, which is a combination of nonspecific symptoms. A recent proposal was made to remove the "sleep" item from the total score, but major methodological flaws (absence of control of medications) do not allow for the validation of this reduced score for field studies $(25,26)$. Moreover, digestive symptoms and fatigue are nonspecific symptoms that can be provoked by many other conditions such as gastrointestinal infections or intense exercise. It was recently shown that dizziness and neurological manifestations can be linked to a ventilatory hyperresponse to hypoxia and thus considered as a good marker of acclimatization (27). Therefore, we should accept the LLS in its original version for field studies, with all its imperfections and subjective drawbacks. No case of HACE was reported. However, several subjects reported symptoms that may account for starting cerebral edema, such as drowsiness, slurred speech, and confusion, but these symptoms rapidly disappeared on descent and no participant reported loss of consciousness.

One may argue that the presence of a subgroup of subjects with previous experience of SHAl may have had an effect on our results. However, the proportion of these subjects in our cohort is limited (7\%) and comparable to a general population (8\%). By reanalyzing our data, it seems that the overall results are not modified after excluding this subgroup. For ex-ample, the incidence rates of SHAI are $19 \%$ in low-susceptible subjects and $27 \%$ in high susceptible subjects, and the difference is still significant $(P=$ 0.023). If we now consider the specific subgroup with previous episodes of SHAI, when both decision tree and $400-\mathrm{m}$ rule were respected, $27 \%$ suffered de novo from SHAI, whereas $64 \%$ were sick if they did not respect the rules $(P=0.04)$, suggesting that the consultation is even more important for subjects with previous episodes of SHAI.

Another limitation is that the compliance of the physician to follow the decision tree and of the subject to follow the prescription (based on the decision tree) was not perfect, with a tendency for an overprescription of $A C Z$ by the physician. One of the objectives of this study was to give an objective tool to limit this prescription to those who would really need it, knowing that ACZ may have some side effects (polyuria, dehydration, paresthesias, digestive symptoms, fatigue) (11) and could interfere with current medications, as seen in trekkers in Nepal (28). In spite of this probable slight overuse of ACZ, a great majority $(80 \%)$ of persons who were low susceptible and did not take ACZ did not suffer from SHAI.

Preacclimatization (in normobaric or hypobaric conditions) before trekking or expedition has been recently developed to "prepare" the subject to the hypoxic stress and limit the occurrence of SHAI $(21,29-31)$. In the present study, no subject had preacclimatized, so we cannot evaluate the efficiency of this hypoxic training method. However, based on previous data, it could be suggested as a countermeasure to reduce the risk of SHAI in high-susceptible subjects $(30,31)$.

In $10 \mathrm{yr}$ from 2008 to 2018 , there is clear tendency for a decrease in the incidence of life-threatening 
forms of altitude sickness (HAPE, HACE). The incidence of HAPE in our cohort $(0.8 \%)$ is lower than what is currently observed in the literature $(2.5 \%-4 \%$ in trekkers) $(1,20)$. However, severe AMS is still observed in around one quarter of the population. The advice for a progressive altitude gain (400-m rule) has been rationalized and documented. Detecting low-susceptible subjects seemed useful to limit and rationalize the prescription of ACZ. Moreover, it allows for the detection of high-susceptible subjects for whom in addition to ACZ prescription, preventive advice (limitation of exercise intensity, proper hydration, respect of the acclimatization rule, avoidance of hypnotics, eventual preacclimatization) is particularly important. However, it is clear that the 400-m rule is sometimes impossible to fulfill because of geographical and practical constraints, such as during the Kilimandjaro climb or when the arrival at HA is abrupt, by flight or by car (Ladakh, Lhassa, La Paz, etc.).

An important aspect of the decision tree based on the SHAI score is that it allows for an individualization of the prescription and advice given to the subject, by taking into account his/her personal physiological response to hypoxia (32) as opposed to a simple interview and general advice proposed by others (33). Altogether, the main result comforting the interest of a prealtitude medical consultation with a hypoxic exercise test leading to the computation of the SHAl score is that the occurrence of SHAl is reduced by more than half $(27 \%-12 \%)$ when the recommendations, in accordance with the SHAl score and the 400-m rule, are respected by the subjects. The limited cost of the consultation (100-120 €) encourages people with no previous experience of high altitude (59\% of our cohort) to perform a hypoxia exercise test and evaluate their personal tolerance to hypoxia.

\section{CONCLUSIONS}

The present observations obtained in a large multicenter cohort confirmed the interest of the SHAl score in predicting the individual risk for SHAl, allowed to determine the precise conditions for an optimized acclimatization (400-m rule) and proposed a rational decision tree for the prescription of ACZ.

We thank all the centers that participated in this study and all the subjects who sent back their field questionnaire. We thank Marie-Carole Paruit for her involvement in the Nantes group. We thank Miss Monique Mendelson for English editing.

The results of the study are presented clearly, honestly, and without fabrication, falsification, or inappropriate data manipulation. The results of the present study do not constitute endorsement by the American College of Sports Medicine. No specific funding was attributed to this study. Each center provided the resources for the routine mountain medicine consultation including the hypoxia exercise test.

There is no conflict of interest for any author to declare. 


\section{REFERENCES}

1. Bärtsch P, Swenson ER. Acute high-altitude illnesses. N Engl J Med. 2013;369:1666-7.

2. Richalet JP, Larmignat P, Poitrine E, Letournel M, Canouï-Poitrine

F. Physiological risk factors for severe high-altitude illness: a prospective cohort study. Am J Respir Crit Care Med.

2012;185:192-8.

3. Canouï-Poitrine F, Veerabudun K, Larmignat P, Letournel M,

Bastuji-Garin S, Richalet JP. Risk prediction score for severe high altitude illness: a cohort study. PLoS One. 2014;9:e100642.

4. Richalet JP, Lhuissier FJ, Larmignat P, Canouï-Poitrine F.

Evaluation de la tolérance à l'hypoxie et susceptibilité aux pathologies de haute altitude. Sci Sports. 2015;30:355-63.

5. Richalet JP, Canouï-Poitrine F, Canou-Poitrine F, Larmignat $P$. Acute high-altitude illnesses. N Engl J Med. 2013;369:1664-5.

6. Coustet B, Lhuissier FJ, Vincent R, Richalet JP.

Electrocardiographic changes during exercise in acute hypoxia and susceptibility to severe high-altitude illnesses. Circulation.

2015;131:786-94.

7. Winkler L, Lhuissier FJ, Richalet JP. Systemic blood pressure at exercise in hypoxia in hypertensive and normotensive patients.

JHypertens. 2017;35:2402-10.

8. Richalet JP, Lhuissier FJ, Jean D. Ventilatory response to hypoxia and tolerance to high altitude in women: influence of menstrual cycle, oral contraception, and menopause. High Alt Med Biol.

2020;21:12-9.

9. Swenson ER. Pharmacology of acute mountain sickness: old drugs and newer thinking. J Appl Physiol (1985). 2016;120:204-15.

10. Davis $C$, Hackett $P$. Advances in the prevention and treatment of high altitude illness. Emerg Med Clin North Am. 2017;35:241-60.

11. Schmickl CN, Owens RL, Orr JE, Edwards BA, Malhotra A. Side effects of acetazolamide: a systematic review and meta-analysis assessing overall risk and dose dependence. BMJ Open Respir Res. 2020;7:e000557.

12. Luks AM, Auerbach PS, Freer L, et al. Wilderness medical society clinical practice guidelines for the prevention and treatment of acute altitude illness: 2019 update. Wilderness Environ Med. 2019;30: S3-18.

13. Sutton JR, Coates G, Houston CS, editors. The Lake Louise consensus on the definition and quantification of altitude illness. In: Hypoxia and Mountain Medicine. Burlington: Queen City Printers Inc; 1992. pp. 327-30.

14. Luks AM, Swenson ER. Travel to high altitude with pre-existing lung disease. Eur Respir J. 2007;29:770-92.

15. Parati G, Agostoni P, Basnyat B, et al. Clinical recommendations for high altitude exposure of individuals with pre-existing cardiovascular conditions: a joint statement by the European Society of Cardiology, the Council on Hypertension of the European Society of Cardiology, the European Society of Hypertension, the International Society of Mountain Medicine, the Italian Society of Hypertension and the Italian Society of Mountain Medicine. Eur Heart J. 2018;39:1546-54.
16. Youden WJ. Index for rating diagnostic tests. Cancer.

1950;3:32-5.

17. Duke CB, Sallade TD, Starling J, et al. Hypertension and acute mountain sickness in Himalayan trekkers in Nepal: an observational cohort study. Wilderness Environ Med. 2020;31:157-64.

18. Lhuissier FJ, Canouï-Poitrine F, Richalet JP. Ageing and cardiorespiratory response to hypoxia. J Physiol. 2012;590:5461-74. 19. Horiuchi M, Endo J, Akatsuka S, Uno T, Jones TE. Prevalence of acute mountain sickness on Mount Fuji: a pilot study. JTravel Med. 2016;23:taw024.

20. Hackett PH, Rennie D, Levine HD. The incidence, importance, and prophylaxis of acute mountain sickness. Lancet. 1976;2:1149-55.

21. Schneider M, Bernasch D, Weymann J, Holle R, Bartsch P. Acute mountain sickness: influence of susceptibility, preexposure, and as-cent rate. Med Sci Sports Exerc. 2002;34:1886-91.

22. Bloch KE, Turk AJ, Maggiorini M, et al. Effect of ascent protocol on acute mountain sickness and success at Muztagh Ata, $7546 \mathrm{~m}$. High Alt Med Biol. 2009;10:25-32.

23. Luks AM. Clinician's corner: what do we know about safe ascent rates at high altitude? High Alt Med Biol. 2012;13:147-52.

24. Richalet JP, Kéromès A, Dersch B, et al. Caractéristiques physiologiques des alpinistes de haute altitude. Sci Sports. 1988;3:89-108.

25. Roach RC, Hackett PH, Oelz O, et al. The 2018 Lake Louise Acute Mountain Sickness Score. High Alt Med Biol. 2018;19:4-6.

26. Richalet JP. Revisiting the Lake Louise score and its 2018 version. XII ISMM World Congress on Mountain Medicine Mountain Nov. 21-24, 2018 Kathmandu, Nepal. High Alt Med Biol. 2018;19:4045. 27. Richalet JP, Larmignat P, Poignard P. Transient cerebral ischemia at high altitude and hyper-responsiveness to hypoxia. High Alt Med Biol. 2020;21:105-8.

28. Keyes LE, Mather L, Duke C, et al. Older age, chronic medical conditions and polypharmacy in Himalayan trekkers in Nepal: an epidemiologic survey and case series. J Travel Med. 2016;23:taw052. 29. Schommer K, Wiesegart N, Menold E, et al. Training in normobaric hypoxia and its effects on acute mountain sickness after rapid ascent to $4559 \mathrm{~m}$. High Alt Med Biol. 2010;11:19-25.

30. Wille M, Gatterer H, Mairer K, et al. Short-term intermittent hypoxia reduces the severity of acute mountain sickness. Scand J Med Sci Sports. 2012;22:e79-85.

31. Fulco CS, Beidleman BA, Muza SR. Effectiveness of preacclimatization strategies for high-altitude exposure. Exerc Sport Sci Rev.2013;41: 55-63.

32. Richalet JP, Canoui-Poitrine F. Pro: hypoxic cardiopulmonary exercise testing identifies subjects at risk for severe high altitude illnesses. High Alt Med Biol. 2014;15:315-7.

33. Bärtsch P. Con: hypoxic cardiopulmonary exercise testing identifies subjects at risk for severe high altitude illnesses. High Alt Med Biol. 2014;15:318-20. 